\title{
Generation of 3D Kimberlite Pipe Models for Resource Classification and Mine Planning: Procedures, Data Sources and Guidelines.
}

\author{
C.M. Hetman, M.D. Diering and W. Barnett \\ SRK Consulting, Canada: chetman@srk.com, mdiering@srk.com,wbarnett@srk.com
}

\section{Introduction}

Traditional sampling, data handling and 3D geological modelling procedures favored by professionals for various mineral commodities in most cases do not apply to primary diamond deposits. Kimberlite pipes, even within small clusters may be characterized by contrasting external pipe morphologies, different pipe infills and a variable distribution of the mineralization. Many pipes include zones that do not contain economic quantities of diamonds. The unique and highly variable geology displayed by most kimberlites, combined with very low diamond contents even within the highest-grade deposits makes kimberlite evaluation challenging. Structured and systematic geology development combined with representative sampling for diamonds is required in order to establish reliable 3D models that may be used for resource classification and mine planning purposes.

This contribution is intended to serve as a practical guideline for the development of 3D models used for the evaluation of a primary diamond deposit within a pipe. Geological development, sampling and modelling procedures are very different for kimberlite sheet systems and will not be addressed here. The procedures and guidelines presented by the authors encapsulate the methodology and procedures followed for the development of 3D models used in support of multiple kimberlite resource classifications and mine plans globally over the last two decades. It must be appreciated that each volcanic complex is different and therefore flexibility with the application of the geological development, sampling and modelling principles applied can be expected.

\section{Geology Development Approach}

The foundation of any 3D pipe model is the geology. Initially the determination of the external pipe shell which contains the mineralization is established. Following this, the internal geology of the pipe is developed, which involves the detailed description and classification of rocks typically examined from drillcores for the purpose of identifying the main pipe infills. This is achieved by establishing the primary mineralogy, textures and xenolith contents within each main phase of kimberlite present. Once the external pipe shell and internal geology have been established then representative sampling for microdiamonds and macrodiamonds can be undertaken in support of resource classification and mine planning. Before 3D modelling is initiated, geological observations and interpretations must be coded in a manner which allows detailed geological information to be uploaded and viewed within a 3D modelling package (Table 1).

\section{Creation of 3D Models}

The development of a 3D geology model involves the generation of 3D solids (using various possible software applications, e.g. Gems / Leapfrog / Vulcan / Minesite) which represent the distribution of specific rock types in space, and includes both the pipe infills and often the enclosing country rock. An external pipe shell model (Fig.1a) represents the divide between the potentally mineralized kimberlite and the sourrounding country rock or waste. Development of such a model is not a straightforward process as it can be very difficult within many pipes to determine if drillcore intervals of country rock are in fact in situ or xenoliths within a pipe. Another common factor may be the presence of marginal or contact breccias that complicate the determination of the position of the pipe wall. Marginal breccias are often associated with with KPK pipes particularly within volcanically immature systems. 


\begin{tabular}{|c|c|c|c|c|c|c|c|c|c|}
\hline Hole ID & From $(m)$ & To $(\mathrm{m})$ & Length $(\mathrm{m})$ & Litho & $\begin{array}{c}\text { Total Dilution } \\
\text { Visual Estimate }\end{array}$ & KIMB Texture & $\begin{array}{l}\text { PIPE Zone } \\
\text { Geology }\end{array}$ & $\begin{array}{l}\text { 3D Model Code } \\
\text { (phase) }\end{array}$ & $\begin{array}{l}\text { 3D Geology } \\
\text { Domain }\end{array}$ \\
\hline FX-17-097 & 0.00 & 15.00 & 15.00 & OVB & 100 & NA & OVB & OVB & OVB \\
\hline FX-17-097 & 15.00 & 88.61 & 73.61 & KIMB & 12 & VK & PIPE & KIMB5 & KIMB5 \\
\hline FX-17-097 & 88.61 & 92.65 & 4.04 & KIMB & 15 & VK & PIPE & RFW & RFW \\
\hline FX-17-097 & 92.65 & 132.15 & 39.50 & KIMB & 10 & RFW & PIPE & KIMB5 & KIMB5 \\
\hline FX-17-097 & 132.15 & 137.41 & 5.26 & KIMB & 5 & RFW & PIPE & KIMB1 & KIMB5 \\
\hline FX-17-097 & 137.41 & 152.43 & 15.02 & KIMB & 12 & RFW & PIPE & KIMB5 & KIMB5 \\
\hline FX-17-097 & 152.43 & 154.34 & 1.91 & GRAN & 100 & NA & XENO & XENO-GRAN & KIMB5 \\
\hline FX-17-097 & 154.34 & 159.50 & 5.16 & KIMB & 20 & RFW & PIPE & KIMB5x & KIMB5x \\
\hline FX-17-097 & 159.50 & 160.82 & 1.32 & GRAN & 99 & NA & XENO & XENO-GRAN & KIMB5x \\
\hline FX-17-097 & 160.82 & 175.75 & 14.93 & GRAN & 100 & NA & EXT-PIPE & GRAN-HOST & EXT-PIPE \\
\hline FX-17-097 & 175.75 & 187.84 & 12.09 & KIMB & 10 & $\mathrm{HK}$ & PIPE & KIMB1 & KIMB1 \\
\hline FX-17-097 & 187.84 & 188.84 & 1.00 & GRAN & 100 & NA & XENO & XENO-GRAN & KIMB1 \\
\hline FX-17-097 & 188.84 & 194.53 & 5.69 & KIMB & 10 & $\mathrm{HK}$ & PIPE & KIMB1 & KIMB1 \\
\hline FX-17-097 & 194.53 & 196.90 & 2.37 & KIMB & 1 & $\mathrm{HK}$ & PIPE & KDYKE-INT & KDYKE-INT \\
\hline FX-17-097 & 196.90 & 199.19 & 2.29 & KIMB & 15 & $\mathrm{HK}$ & PIPE & KIMB1 & KIMB1 \\
\hline FX-17-097 & 199.19 & 201.56 & 2.37 & GRAN & 90 & $\mathrm{NA}$ & XENO & XENO-GRAN & KIMB1 \\
\hline FX-17-097 & 201.56 & 203.29 & 1.73 & KIMB & RFW & RFW & PIPE & RFW & RFW \\
\hline FX-17-097 & 203.29 & 210.22 & 6.93 & GRAN & 100 & NA & EXT-PIPE & GRAN-HOST & EXT-PIPE \\
\hline FX-17-097 & 210.22 & 216.83 & 6.61 & GRAN & 100 & NA & EXT-PIPE & GRAN-HOST & EXT-PIPE \\
\hline FX-17-097 & 216.83 & 218.70 & 1.87 & KIMB & 35 & KPK & PIPE & KIMB6 & KIMB6 \\
\hline FX-17-097 & 218.70 & 357.33 & 138.63 & GRAN & 97 & $\mathrm{NA}$ & XENO & XENO-GRAN & KIMB6 \\
\hline FX-17-097 & 357.33 & 369.33 & 12.00 & KIMB & 35 & KPK & PIPE & KIMB6 & KIMB6 \\
\hline FX-17-097 & 369.33 & 371.77 & 2.44 & GRAN & 100 & NA & XENO & XENO-GRAN & KIMB6 \\
\hline FX-17-097 & 371.77 & 387.80 & 16.03 & KIMB & 2 & $\mathrm{HK}$ & PIPE & RFW & RFW \\
\hline FX-17-097 & 387.80 & 406.47 & 18.67 & KIMB & 40 & KPK & PIPE & KIMB6x & KIMB6x \\
\hline FX-17-097 & 406.47 & 469.77 & 63.30 & KIMB & 45 & KPK & PIPE & KIMB6x & KIMB6x \\
\hline FX-17-097 & 469.77 & 471.58 & 1.81 & KIMB & 10 & $\mathrm{HK}$ & PIPE & KIMB4 & KIMB4 \\
\hline FX-17-097 & 471.58 & 473.50 & 1.92 & GRAN & 100 & NA & XENO & XENO-GRAN & KIMB4 \\
\hline FX-17-097 & 473.50 & 477.40 & 3.90 & KIMB & RFW & HK & PIPE & KIMB4 & KIMB4 \\
\hline FX-17-097 & 477.40 & 479.43 & 2.03 & GRAN & 100 & NA & XENO & XENO-GRAN & KIMB4 \\
\hline FX-17-097 & 479.43 & 483.17 & 3.74 & KIMB & 10 & HK & PIPE & KIMB4 & KIMB4 \\
\hline FX-17-097 & 483.17 & 525.00 & 41.83 & FENITE & 100 & $\mathrm{NA}$ & FENITE & FENITE & FENITE \\
\hline FX-17-097 & 525.00 & 528.63 & 3.63 & GRAN & 100 & NA & EXT-PIPE & GRAN-HOST & EXT-PIPE \\
\hline FX-17-097 & 528.63 & 534.01 & 5.38 & KIMB & 1 & $\mathrm{HK}$ & KDYKE-EXT & KDYKE-EXT & KDYKE-EXT \\
\hline FX-17-097 & 534.01 & 537.24 & 3.23 & FENITE & 100 & NA & FENITE & FENITE & FENITE \\
\hline FX-17-097 & 537.24 & 547.81 & 10.57 & GRAN & 100 & NA & EXT-PIPE & GRAN-HOST & EXT-PIPE \\
\hline FX-17-097 & 547.81 & 549.32 & 1.51 & KIMB & 2 & $\mathrm{HK}$ & KDYKE-EXT & KDYKE-EXT & KDYKE-EXT \\
\hline FX-17-097 & 549.32 & 575.00 & 25.68 & GRAN & 100 & NA & EXT-PIPE & GRAN-HOST & EXT-PIPE \\
\hline
\end{tabular}

Table 1: Sample of a geological coding table developed from core logging and petrography.
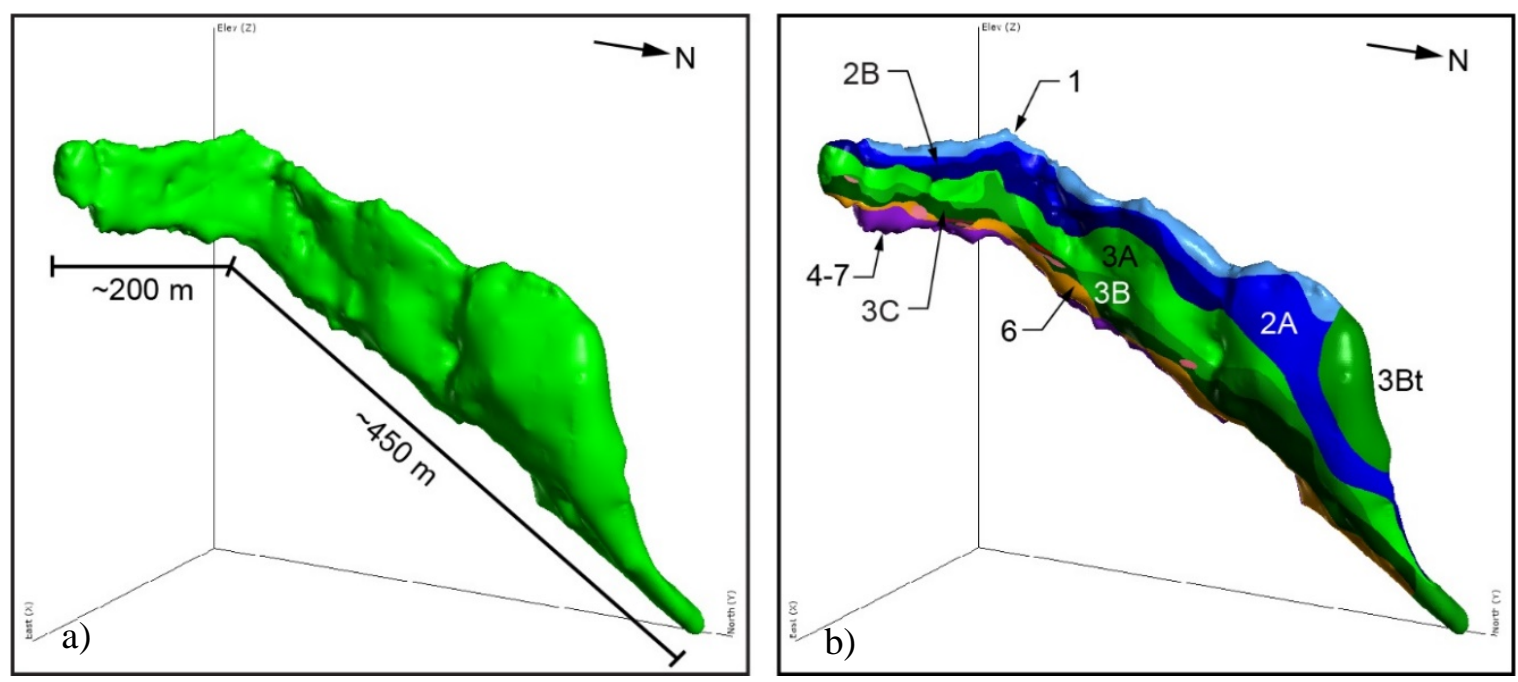
Figure 1: 3D geology models of the Kelvin kimberlite pipe, NWT, Canada. a) external pipe shell, b) internal geology with different phases highlighted by the different coloured solids, with corresponding 3D geology domain codes.

The external shell model or "pipe shell" is developed by the investigation of the "Pipe Zone" data (Table 1) and then by developing a geologically reasonable interpretation for the external shape. This involves not only an understanding of the textural varieties of kimberlite that have been intersected (VK vs. HK), but also an understanding of the possible volcanic or depositional processes (i.e. explosive fragmentation / effusive / intrusive / resedimentation) responsible for the development of specific textures present. Each of these processes and the nature of the host rock geology are associated with different styles of emplacement and resultant pipe shapes. Also critical to the development of a reliable pipe shell, is a good understanding of the host rock geology and xenoliths within the kimberlite.

Following the development of the external shell, the internal geology is developed by the interpretation of the "3D Model Code" data (Table 1). Like the external shell, the internal distribution of the phases of kimberlite are controled by the volcanic history of the pipe as well as the geological processes responsible for the development of the different textural varieties of kimberlite present. The identification of the "phases" of kimberlite requires not only detailed logging of drillcores and supporting petrographic investigation, but is supported by multiple data sets including microdiamond and macrodiamond results, mantle derived indicator mineral studies, olivine line scans, and dilution line scans. Other studies supporting the definition of the internal kimberlite phases may be applied, including groundmass compositional studies, whole rock geochemistry or spectral scanning and geophysical properties.

Once the kimberlite phases have been established and the "3D Model Codes" have been assigned to all intervals, they are reviewed in 3D. The development of the 3D internal geology model actually represents a reconstruction of the volcanic history of the pipe (Fig.1b). The actual internal geometry of the pipe is determined by the distribution, orientation and nature of the internal contacts between the various phases present. Because the pipes are filled by multiple phases of kimberlite that are emplaced by a number of volcanic events over time, mixing may occur and displaced blocks of earlier phases can be found within younger phases. To cater for these complications the final internal geology model is developed by the use of the "3D Domain Code" (Table 1.) which allows the geologist to group intervals, classified by a particular "3D Model Code" into a geological domain. Each geological domain is dominated (75\% or greater volume) by a single phase of kimberlite but may contain blocks of other kimberlite phases. The most challenging part of the 3D modelling process is the extrapolation of geology and grade into undrilled and unsampled portions of a pipe. This is achieved by interpretation constrained by adequate technical understanding of relevant volcanological processes, consistent with the textures and controlling structures identified within each phase of kimberlite

\section{Conclusions}

The quality of any 3D geology model produced is a function of the complexity of the geology of a particular pipe being investigated. Also the number and distribution of drillholes or mining exposures available for examination and thin sections available, as well as the amount of time completed on the investigation are critical factors. The experience of the geology team will have a significant impact on the quality of the model generated. The preservation state of the rocks being investigated impact the amount of information that may be revealed; rocks that are extensively altered or weathered may mask important textural and mineralogical information required for accurate classification. Finally the grade of a particular pipe and the types of macrodiamonds present will impact the amount of drilling and sampling required to facilitate the development of a reliable model in support of resource classification and mine planning. All models produced must be considered dynamic as the models will evolve as additional information and investigations are completed through subsequent drilling or mining activities. 